\title{
Effects of Plastic Waste Materials on Geotechnical Properties of Clayey Soil
}

\author{
Hussein Jalal Aswad Hassan ${ }^{1}$ (D) Jabar Rasul $^{2}$ (D) $\cdot$ Maleaha Samin $^{3}$
}

Accepted: 30 November 2020/ Published online: 4 January 2021

(C) The Author(s) 2021

\begin{abstract}
Recently, the use of plastic products, such as polyethylene (PE) bottles and polypropylene (PP), has been significantly increased, which may lead to many environmental issues. Therefore, it is important to find methods to manage these waste materials without causing any ecological hazards. One of these methods is to use plastic wastes as soil stabiliser materials. In this study, PE and PP have been used in the form of fibres. The effect of the stabilisation was evaluated through carrying out standard laboratory tests. These tests have been conducted on natural and stabilised soils with four fibre contents $(1 \%, 2 \%, 3 \%$, and $4 \%)$ of the soil weight. The tests included the standard compaction test, unconfined compressive strength (UCS) test, California Bearing Ratio (CBR) test, and resilient modulus (Mr) tests. In all these tests, the fibre content was added in two lengths, which were $1.0 \mathrm{~cm}$ and $2.0 \mathrm{~cm}$. Laboratory test results revealed that the plastic pieces decrease maximum dry density (MDD) and optimum moisture content $(\mathrm{OMC})$ of the stabilised soils, which are required for the construction of embankments of lightweight materials. In addition, there was a significant improvement in the UCS of soils by 76.4 and $96.6 \%$ for both lengths of PE fibres and $57.4 \%$ and $73.0 \%$ for both lengths of PP fibres, respectively. Results of the CBR tests demonstrated that the inclusion of plastic fibres in clayey soils improves the strength and deformation behaviour of the soil especially with $4 \%$ fibre content for both lengths $1.0 \mathrm{~cm}$ and $2.0 \mathrm{~cm}$, respectively, to a figure of 185 to $150 \%$ for PE and PP, respectively. Furthermore, the results of the Mr tests demonstrated that the mechanical properties improved to an extent. For an increase in fibre content, the resilient modulus increased by about $120 \%$ at $4 \%$ fibre content for PE. However, for PP, improvement in resilient modulus declined at $3 \%$ fibre content. Therefore, for soil stabilisation with fibre material, optimum fibre content shall be sought.
\end{abstract}

Keywords Soilstabilisation · Plastic waste materials · Fibre content $\cdot$ Geotechnical property tests

Jabar Rasul

jabarrasulmnt@gmail.com; jabar.rasul@watermanaspen.co.uk

Extended author information available on the last page of the article 


\section{Introduction}

Disposal of waste materials is becoming a predominant issue for most countries in the world. The accumulation of these waste materials in huge quantities is causing both environment and financial problems. According to Awuchi (2019), the average plastic waste generation is estimated at 15.4 billion pieces per day. The most prevalent waste materials are plastic waste materials. These materials are the most usable material types in our daily life. Plastic wastes are produced in massive quantities such as plastic bottles, which are made from polyethylene terephthalate (PET), and plastic sack and carpet, which are made from polypropylene (PP). Polyethylene products are considered to be the major components of waste materials in Kurdistan/Iraq. Hanna and Mosa (2012) reported that in Duhok City, more than 5000 tons of polyethylene $\left(500-\mathrm{cm}^{3}\right.$ bottle capacity) is produced as waste materials every year. Despite its benefits in our daily life, plastic pose negative impacts on the environment and health. Since the majority of plastics are not biodegradable and can sustain for many years, many countries are planning to decrease or prevent the effect of plastic materials through efficient recycling and reusing these materials in a wide range of fields.

Many researchers have carried out studies to find effective methods to reduce the pollution of these materials including recycling and reusing these materials in civil engineering applications as a solution to preserve the environment from the pollution of plastic waste materials. An effective method to utilise these materials is to be used as a soil stabiliser for road construction (Tatone et al. 2018). Traditional soil stabilisers such as cement and lime are widely used for improving the geotechnical properties of weak soils (Sherwood 1993; Yadav et al. 2018 and Yadav and Tiwari 2016). The effectiveness of these materials on improving the properties of soils is confirmed by various researchers (Bell 1996; Little 1995; Rout et al. 2012; Rasul et al. 2015; Rasul et al. 2016; Yadav and Tiwari 2017; Rasul et al. 2018). However, the high usage of these materials makes them non-cost-effective (Obo and Ytom 2014). Therefore, many researchers attempt to find alternative cost-effective soil stabilisers such as plastic, tyre chips, and rice husk.

Using plastic wastes for soil stabilisation can improve the foundation layers of pavement (Khattab et al. 2011). Thus, this can solve the problem of wastes by reducing the quantities and recycling these materials for enhancing the properties of soils. One method of using plastic for soil stabilisation is to use the plastic in the form of discrete fibres (Yetimoglu and Salbas 2003), because when plastic materials are merged with soils, they behave similar to fibre-reinforced soil. Several researches have been conducted to investigate the effectiveness of plastic waste materials in the form of discrete fibres on properties of soils (Ziegler et al. 1998; Babu and Chouksey 2011; Mondal 2012; Ahmadinia et al. 2012; Modarres and Hamedi 2014; Fauzi et al. 2015; Changizi and Haddad 2015; Rawat and Kumar 2016; Peddaiah et al. 2018; Salimi and Ghzavi 2019). These researchers found that using plastic waste materials for soil stabilisation will improve the properties of weak soils such as an increase in UCS, CBR, and Mr and a decrease in the soil plasticity.

This study investigates the effect of using plastic waste as fibre-shaped waste materials on geotechnical properties of soils. A number of standard geotechnical laboratory tests were performed in order to identify the effect of length and contents of fibres that are randomly distributed throughout the soil. These tests consisted of soil 
index properties, standard compaction test (proctor test), unconfined compressive strength test, California Bearing Ratio test, and resilient modulus tests.

\section{Experimental Programme}

\subsection{Materials and Methodology}

\subsubsection{Soil}

The soil used in this study was collected from the Hawshki area, West of Duhok City, Kurdistan Region, Iraq. The sample is divided into four equal parts by removing two diagonally opposite parts and then mixing two remaining parts properly. The physical properties of the soil are shown in Table 1; this soil is classified as clay soil according to the American Society for Testing and Materials (ASTM) with about 93\% silt and clay.

\subsubsection{Plastic Waste Material}

In this study, polyethylene terephthalate (PE) (water bottles) and polypropylene (PP) (woven polypropylene bags) wastes were used as fibre stabilisers as shown in Fig. 1. Plastic fibres were prepared by cutting waste bottles and bags into two sizes in lengths of 1.0 and $2.0 \mathrm{~cm}$ and in widths of 2.5 to $3.0 \mathrm{~mm}$ each as shown in Fig. 2. The fibre contents were applied at $1 \%, 2 \%, 3 \%$, and $4 \%$ of dry weight of the clayey soil.

\subsection{Laboratory Tests}

In this study, to examine the strength and mechanical properties of both native and stabilised soils, different laboratory tests were conducted including the determination of index properties of unstabilised soil and standard proctor compaction, UCS, CBR (soaked), and $\mathrm{Mr}$ for stabilised and unstabilised soils. All tests were conducted according to ASTM, except resilient modulus, which is conducted in accordance with

Table 1 Physical properties of the native soil

\begin{tabular}{lcl}
\hline Soil properties & Results & Standards \\
\hline Specific gravity (Gs) & 2.7 & ASTM D854-02 \\
Liquid limit (\%) & 48.2 & ASTM D4318-00 \\
Plastic limit (\%) & 29.1 & ASTM D4318-00 \\
Plasticity index (\%) & 19.1 & ASTM D4318-00 \\
Maximum dry density $\left(\mathrm{kg} / \mathrm{m}^{3}\right)$ & 1645 & ASTM D698 \\
Optimum moisture content (\%) & 21 & ASTM D698 \\
Sand (\%) & 7 & \\
Silt (\%) & 42 & \\
Clay (\%) & 51 & ASTM D2487-00 \\
Soil classification (USCS) & $\mathrm{CL}$ & \\
\hline
\end{tabular}




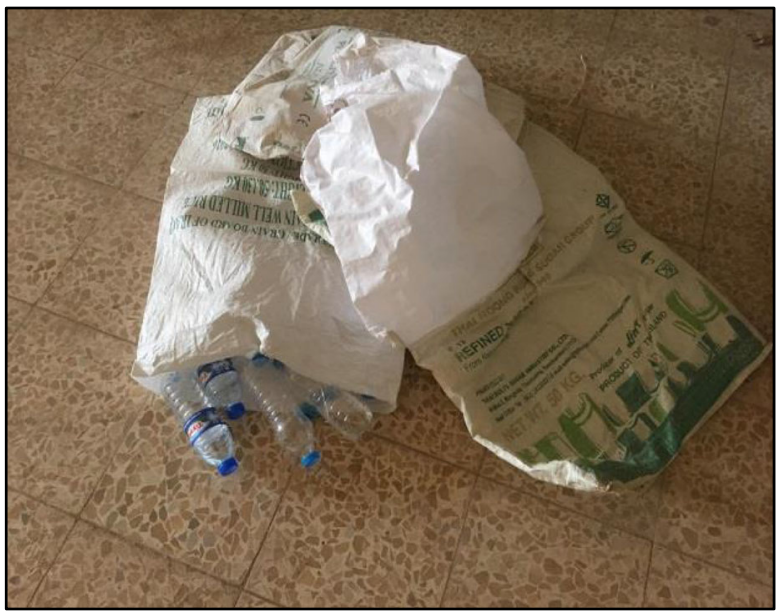

Fig. 1 Plastic waste materials used in the study

AASHTO T307. For all tests, the adopted content of fibres was first manually mixed into the air-dried soil in small increments. Considerable care was taken to achieve homogeneous mixture during the mixing process. Then, the required water was added as shown in Fig. 3.

\subsubsection{Compaction Test}

The laboratory compaction tests were performed in accordance with the ASTM D698 procedure. The purpose of this test is to determine the effect of plastic fibre on optimum moisture content (OMC) and maximum dry density (MDD) of stabilised soils and to use OMC that was obtained in this test for preparing samples for UCS, CBR, and $\mathrm{Mr}$ tests, dry density, and optimum moisture content.
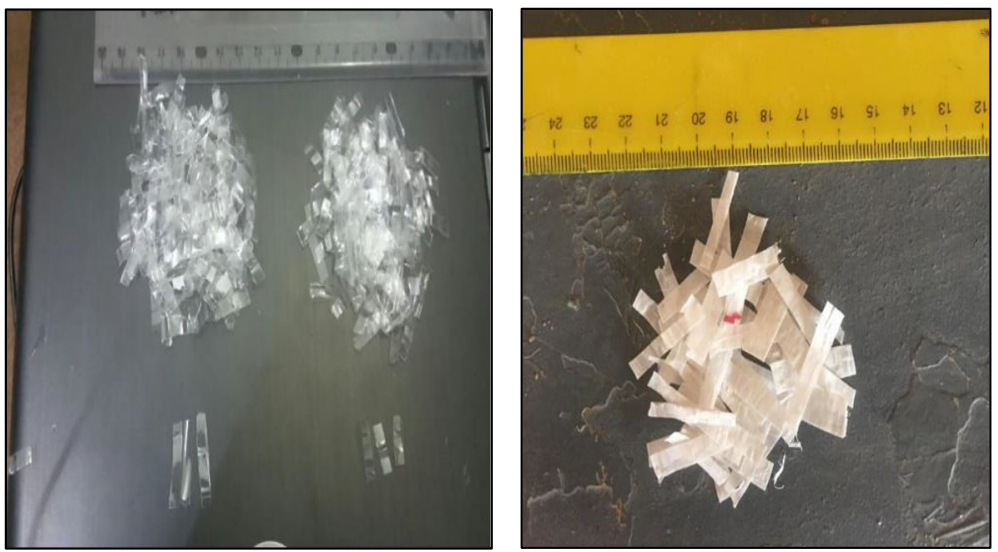

Fig. 2 Sample of the fibres used in this study 

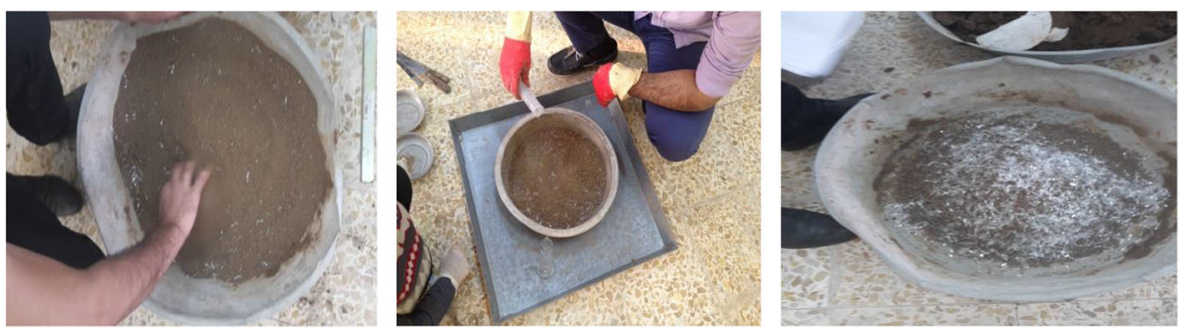

Fig. 3 Mixing the fibres with soil

\subsubsection{Unconfined Compressive Strength Test}

This test was conducted to investigate the effect of inclusion of plastic waste pieces on the unconfined compressive strength of soils. The test was performed in accordance with ASTM D2166. All the UCS test specimens were prepared at their respective MDD and OMC. All prepared specimens were air-dried in the open laboratory environment and were cured for 7 days.

\subsubsection{California Bearing Ratio Test}

For the CBR test, cylindrical specimens were prepared using their MDD at $\mathrm{OMC}$ in a rigid metallic cylinder mould with an inside diameter of $150 \mathrm{~mm}$ and a height of $175 \mathrm{~mm}$. A mechanical loading machine equipped with a movable base that moves at a uniform rate of $1 \mathrm{~mm} / \mathrm{min}$ and the calibrated proving ring is used to record the load. For this, static compaction is carried out through keeping the mould assembly in the compression machine and compacting the soil by pressing the displacer disc till the level of the disc reaches the top of the mould. This test was carried out in accordance with ASTM D1883. In this study, the soaked specimens were made at OMC as determined from the standard compaction test.

\subsubsection{Resilient Modulus (Mr)}

The repeated load from a triaxial test has also been conducted in this study to investigate the effect of plastic material stabilisers on resilient modulus values that represent the mechanical property of the soils. This parameter is significantly important to assess the performance of material under the repeated load of moving vehicles. In this test, a series of repeated loads are applied to the soil samples including the rest period. This test is conducted by using an ELE triaxial device and in accordance with the AASHTO T307 testing protocol as this standard is mostly used for determining resilient modulus in the laboratory. The haversine type of load is used with duration of a 0.1 -s and 0.9 -s recovery period. The sample dimensions are $100 \mathrm{~mm}$ in diameter and $200 \mathrm{~mm}$ in height. The curing period for all samples were 7 days. AASHTO T307 standards recommend three confining stresses in three cycles $(41.36,27.57$, and $13.78 \mathrm{kPa})$ and five deviatoric stresses $(13.79,27.58,41.39,55.161$, and $68.95 \mathrm{kPa})$.

The details of the sequence and cycles can be seen in Table 2 . 
Table 2 Mr test loading sequence

\begin{tabular}{lllll}
\hline Sequence no. & Confining pressure $(\mathrm{kPa})$ & Cyclic stress $(\mathrm{kPa})$ & Constant stress $(\mathrm{kPa})$ & Load cycle no. \\
\hline 0 & 41.37 & 24.82 & 2.76 & 1000 \\
1 & 41.37 & 12.41 & 1.38 & 100 \\
2 & 41.37 & 24.82 & 2.76 & 100 \\
3 & 41.37 & 37.23 & 4.14 & 100 \\
4 & 41.37 & 49.64 & 5.52 & 100 \\
5 & 41.37 & 62.05 & 6.89 & 100 \\
6 & 27.58 & 12.41 & 1.38 & 100 \\
7 & 27.58 & 24.82 & 2.76 & 100 \\
8 & 27.58 & 37.23 & 4.14 & 100 \\
9 & 27.58 & 49.64 & 5.52 & 100 \\
10 & 27.58 & 62.05 & 6.89 & 100 \\
11 & 13.79 & 12.41 & 1.38 & 100 \\
12 & 13.79 & 24.82 & 2.76 & 100 \\
13 & 13.79 & 37.23 & 4.14 & 100 \\
14 & 13.79 & 49.64 & 5.52 & 100 \\
15 & 13.79 & 62.05 & 6.89 & 100 \\
\hline
\end{tabular}

\section{Results and Discussion}

\subsection{Compaction Test}

Figures 4, 5, 6, 7, 8, 9, 10, and 11 show the results of the compaction tests for the native soils and soils stabilised with PE and PP stabilisers of $1.0 \mathrm{~cm}$ and $2.0 \mathrm{~cm}$ in length at different stabiliser content ratios. For the native soil, the OMC was $21 \%$ and the MDD was $1645 \mathrm{~kg} / \mathrm{m}^{3}$.

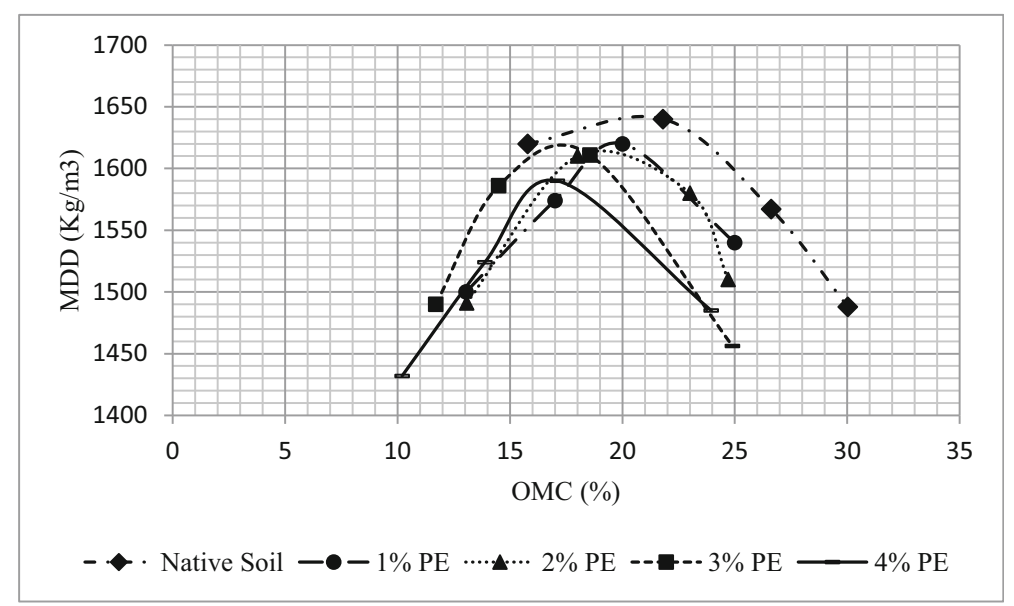

Fig. 4 Proctor test results for 1-cm length of $\mathrm{PE}$ at different stabiliser contents 


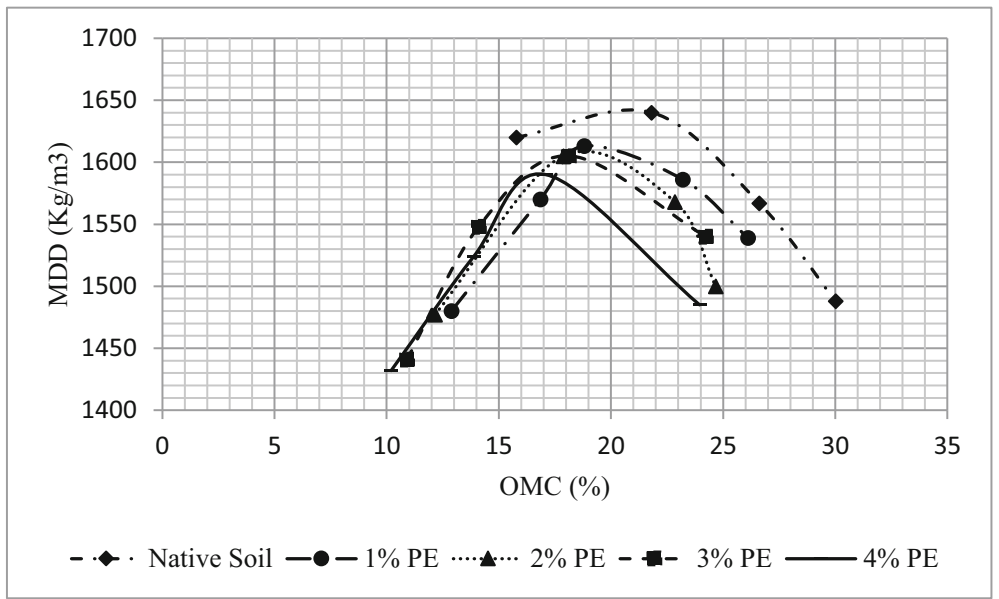

Fig. 5 Proctor test results for 2-cm length of PE at different stabiliser contents

As it can be seen in the compaction test results, the OMCs and MDDs decrease for the stabilised soils compared to the native soils. The decrease in both of these two properties can be noticed as the fibre content increases. These can be seen clearly in Figs. 6 and 7. This consistent trend of effect of fibre content increase cannot be seen for the stabilisation with PP fibres (see Figs. 8, 9, 10, and 11).

For the soils stabilised with PE at various fibre contents of $1.0 \mathrm{~cm}$ and $2.0 \mathrm{~cm}$ in length, the results demonstrated a similar trend in terms of reduction in OMC. The results revealed that by increasing the PE percent, OMC was decreased. The reduction value for $1.0-\mathrm{cm}$ and $2.0-\mathrm{cm}$-length PE is from $20 \%$ for $1 \%$ PE content to $17 \%$ for $4 \%$ PE content.

Similarly, the MDD for both lengths at all fibre contents showed reduction in a value with the increase in the PE percent. The highest decrease was obtained at $4 \%$ fibre content for both lengths by $55 \mathrm{~kg} / \mathrm{m}^{3}$. These data clearly state that by adding more PE

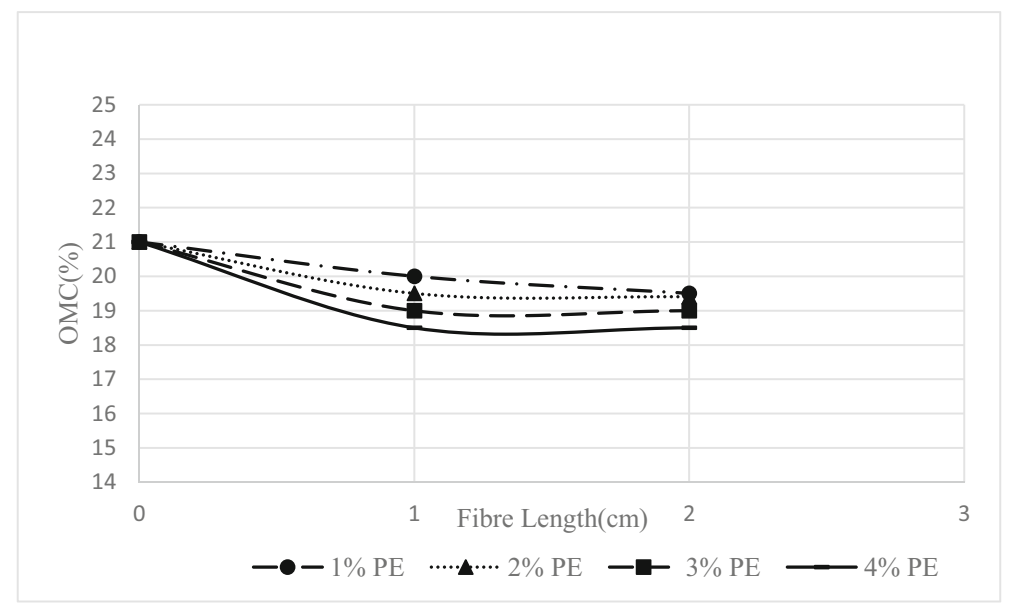

Fig. 6 Effect of the PE ratio on OMC 


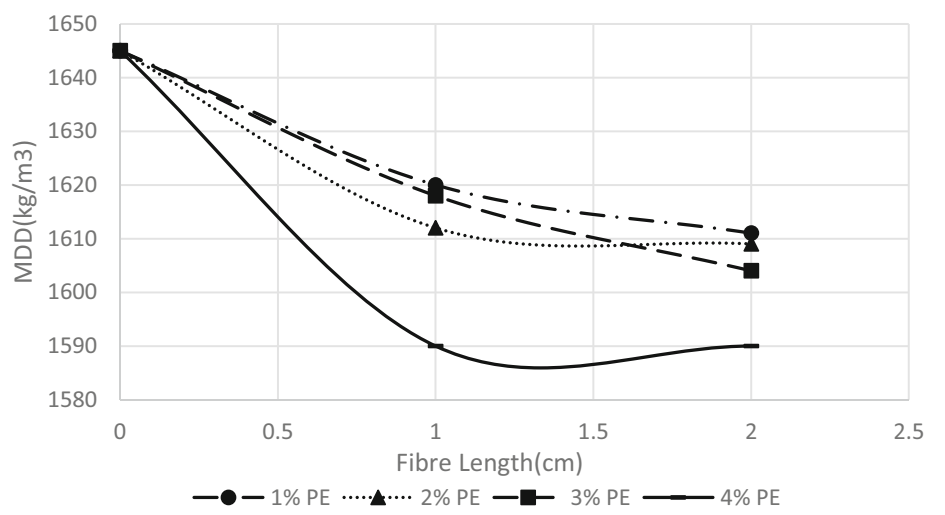

Fig. 7 Effect of the PE ratio on MDD

percent, both OMC and MDD values decrease; also, if the length of PE increases from 1.0 to $2.0 \mathrm{~cm}$, the OMC decreases more as shown in Figs. 6 and 7, except for MDD at $3 \%$ showing an odd trend. These results were similar to those obtained by Bala (2013), Nsaif (2013), Dhatrak and Konmare (2015a, b), and Kumar et al. (2018). Kumar et al. (2018) cut the PE into $1.0 \mathrm{~cm}, 2.0 \mathrm{~cm}$, and $3.0 \mathrm{~cm}$ lengths at various fibre contents of $0 \%, 0.2 \%, 0.5 \%$, and $0.8 \%$ and $1.0 \%$ of the dry weight of soil. They found that as the length and content of the plastic increase, the value of MDD decreases. They concluded that the highest reduction was found when plastic content was $1 \%$ of the dry weight of the soil and the optimum length of plastic strip inclusion was $3.0 \mathrm{~cm}$. Nsaif (2013) investigated the effect of the plastic wastes that were made from plastic bottles with fibre contents of $0,2,4,6$, and $8 \%$ of the dry weight of the soil on the behaviour of the stabilised soil. Nsaif (2013) found that the increase in plastic content decreases both OMC and MDD of soils. The highest decrease was found at $8 \%$ plastic content.

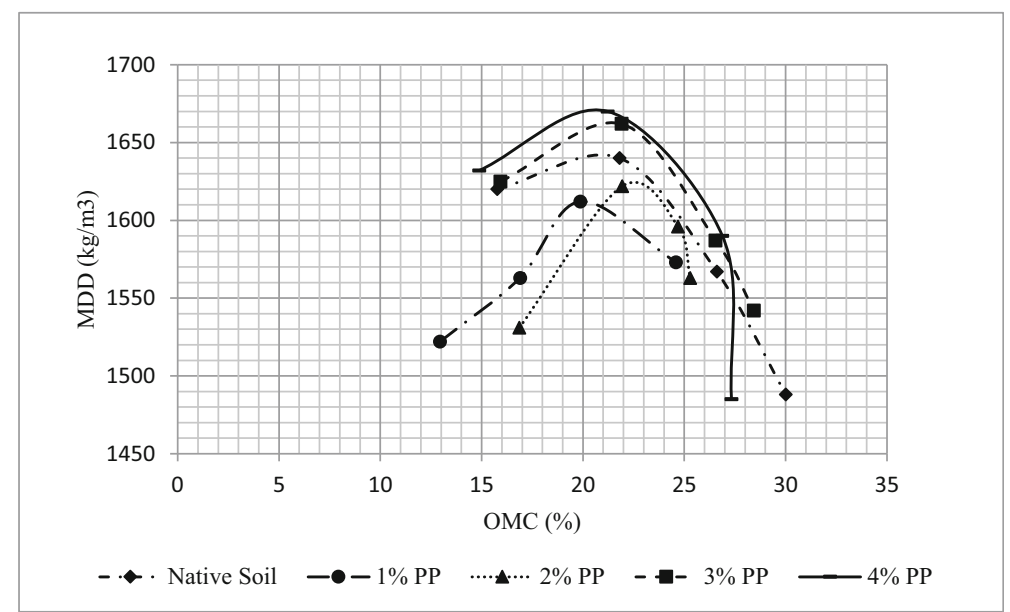

Fig. 8 Proctor test results for 1-cm length of PP at different stabiliser contents 


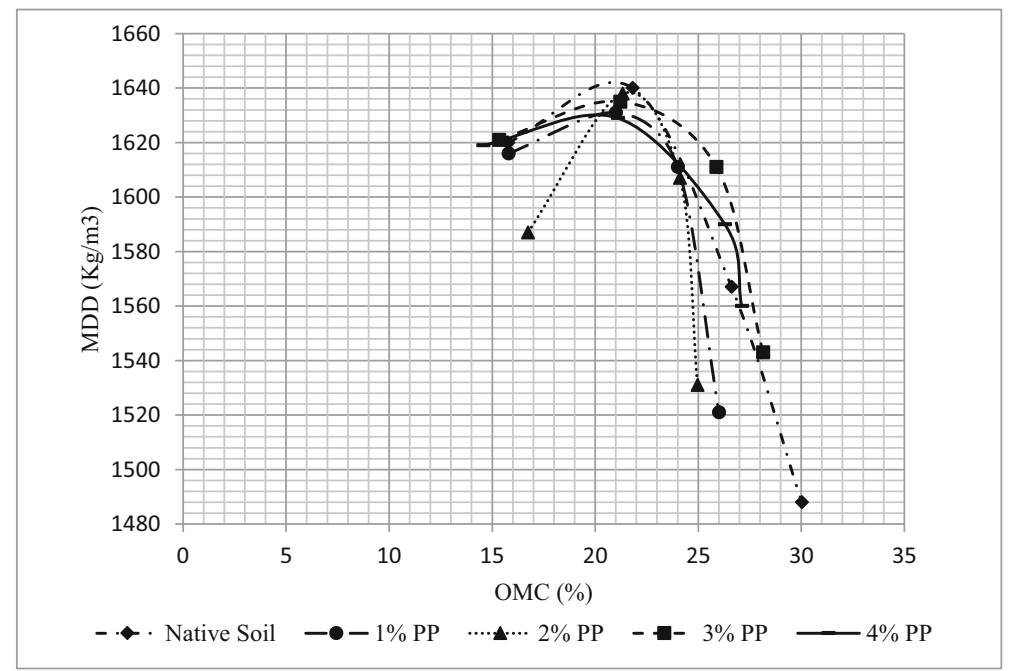

Fig. 9 Proctor test results for 2-cm length of PP at different stabiliser contents

Soil stabilised with PP at various fibre contents of $1.0 \mathrm{~cm}$ and $2.0 \mathrm{~cm}$ in length showed different behaviour in terms of OMC and MDD. It was found that for $1.0-\mathrm{cm}$ length, MDD at $1 \%$ and $2 \%$ fibre content was decreased by 35 and $20 \mathrm{~kg} / \mathrm{m}^{3}$, respectively. However, after that, by increasing the fibre content with $3 \%$ and $4 \%$, MDD was increased by 20 and $30 \mathrm{~kg} / \mathrm{m}^{3}$, respectively. For $2.0-\mathrm{cm}$ fibre length, MDD was decreased with the increase in PP contents. The highest decrease was at $4 \%$ fibre content by $25 \mathrm{~kg} / \mathrm{m}^{3}$. Taha et al. (2020) investigated the effects of polypropylene fibre (PF) $12.0 \mathrm{~mm}$ in length on the mechanical behaviour of clayey soils. They mixed the soil with $0 \%, 1.5 \%, 2.25 \%$, and $3 \%$ of PF content by the soil weight. Their study concluded that the increase in fibre content results in an increase in MDD and a decrease in $\mathrm{OMC}$ with an optimum fibre content of $3 \%$.

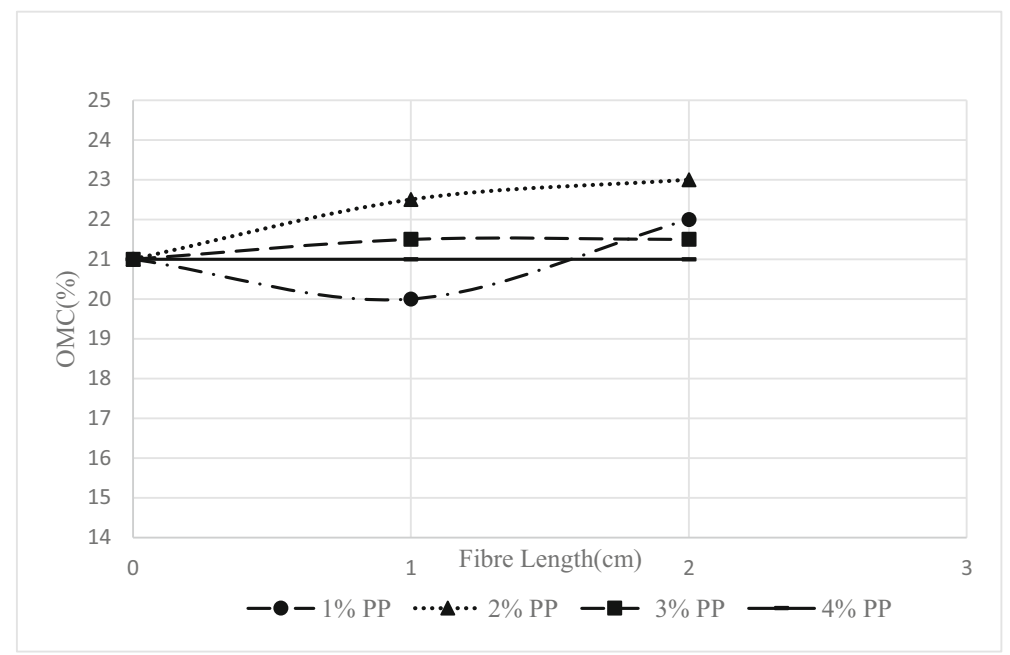

Fig. 10 Effect of the PP ratio on OMC 


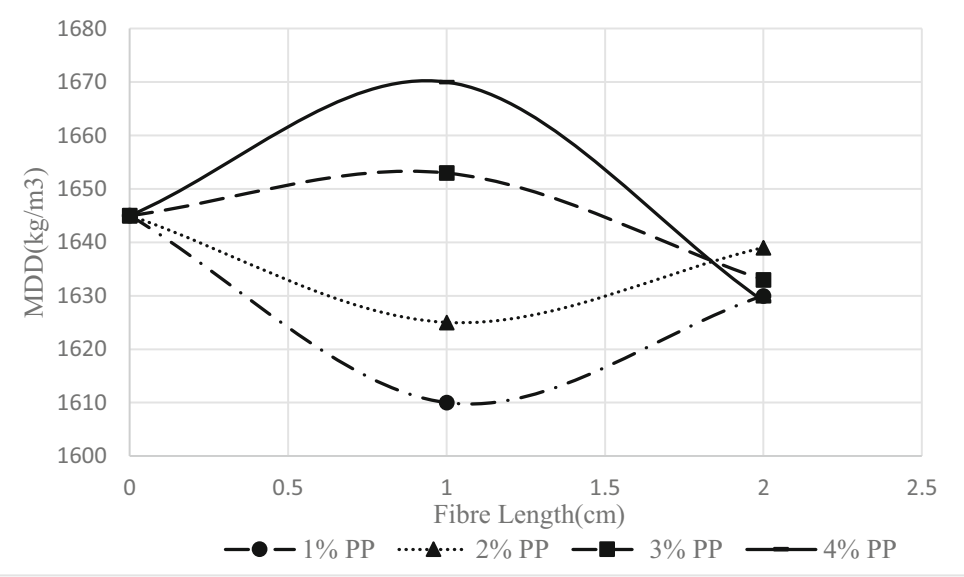

Fig. 11 Effect of the PP ratio on MDD

For $1.0-\mathrm{cm}$ fibre length, $2 \%$ fibre content showed an increase in OMC with $2 \%$. However, for other fibre contents, no significant changes in OMC occurred. For $2.0-\mathrm{cm}$ fibre length at all fibre contents, OMC increased very slightly.

Generally, these data reveal that the inclusion of plastic waste materials in soils decreases the OMC. This is due to the fact that plastics are not absorbent materials compared to clay soils, which have high affinity to water due to its surface tension (Nsaif 2013). Regarding MDD, the results show no improvement in MDD after the addition of PE. This could be attributed to the low specific gravity of PE (Puppala and Musenda 2007; Gardete et al. 2019). This could be an advantage for using PE as a stabiliser to be one of the components for construction of embankments. However, improvements were found by the addition of PP with $3 \%$ and $4 \%$ fibre contents. This could be attributed to ease in mixing with soil, which behaves as multifilament fibre during the mixing action (Olgun 2013). Therefore, PP may be more efficient than PE in terms of its impacts on distribution and bonding of soil particles. In addition, the decrease in MDD will be due to the low specific gravity of fibres (Nsaif 2013).

\subsection{Unconfined Compressive Strength (UCS) Test}

Table 3 shows the results of UCS; as it can be seen, the addition of PE and PP fibre increased the stabilised soil strength considerably compared to the native soil strength, which was $148 \mathrm{kPa}$. However, this increase in UCS has an optimum based on the ratio of fibre content, as can be seen in Fig. 8, in which the increase in fibre content is up to $1 \%$; thereafter, the curve flattens and continues at the same strength with the increase in fibre content. The comparison between PE and PP shows that the former has higher UCS values than the latter for $1.0-\mathrm{cm}$ and $2.0-\mathrm{cm}$ lengths of the fibre. In all cases, the 2.0 -cm-length fibre results are higher than $1.0-\mathrm{cm}$-length fibre results.

For soil stabilised with $1.0-\mathrm{cm}$ and $2.0-\mathrm{cm}-$ length PE fibre, the optimum fibre content was $1 \%$. The value of UCS increased from $148 \mathrm{kPa}$ (native soil) to $261 \mathrm{kPa}$ (1.0-cm fibre length) and $291 \mathrm{kPa}(2.0-\mathrm{cm}$ fibre length) with an improvement by 76.4 
Table 3 UCS test results for PE and PP fibres

\begin{tabular}{llll}
\hline Fibre content $(\%)$ & Fibre length $(\mathrm{cm})$ & UCS $(\mathrm{kPa}) \mathrm{PE}$ & UCS $(\mathrm{kPa}) \mathrm{PP}$ \\
\hline 0 & - & 148 & 148 \\
1 & 1 & $261(+76.4 \%)$ & $233(+57.4 \%)$ \\
& 2 & $291(+96.6 \%)$ & $256(+73 \%)$ \\
2 & 1 & $246(+66.2 \%)$ & $223(+50.7 \%)$ \\
& 2 & $266(+79.7 \%)$ & $238(+60.8 \%)$ \\
3 & 1 & $245(+65.5)$ & $221(+49.3 \%)$ \\
& 2 & $272(+83.8)$ & $242(+63.5 \%)$ \\
4 & 1 & $242(+63.5)$ & $220(+48.6 \%)$ \\
& 2 & $276(+86.5)$ & $245(+65.5 \%)$ \\
\hline
\end{tabular}

The numbers in parenthesis are representing the percentage of improvement in UCS

and $96.6 \%$, respectively. The lowest increase in UCS was at $4 \%$ fibre content for 1.0 $\mathrm{cm}$ fibre length and $2 \%$ fibre content for $2.0-\mathrm{cm}$ fibre length.

Similarly, for soil stabilised with $1.0-\mathrm{cm}$ and $2.0-\mathrm{cm}$ lengths of PP fibre, the optimum fibre content was $1 \%$. The value of UCS increased from $148 \mathrm{kPa}$ (native soil) to $233 \mathrm{kPa}$ (1-cm fibre length) and $256 \mathrm{kPa}(2.0-\mathrm{cm}$ fibre length) with an improvement by 57.4 and $73 \%$, respectively. The lowest increase in UCS was at $4 \%$ fibre content for $1.0-\mathrm{cm}$ fibre length and $2 \%$ fibre content for $2.0-\mathrm{cm}$ fibre length.

Muntohar (2009) stated that when soils were stabilised with fibres, the fibre transferred the applied load to the frictional interface between soil particles and fibres. As fibre contents increase, the interfaces between soil and fibres increase, and this leads to increasing the friction between soil particles and fibres (Olgun 2013). This makes it difficult for soil particles that are surrounding the fibres to change their position and thus enhance the soil cohesion between soil particles (Muntohar et al. 2013). In addition, the high tensile strength of fibre plays a significant role in making the soil to withstand more loads and increase its UCS (Tang et al. 2007a, b). It is known that PE has higher tensile strength than PP; therefore, the UCS of soils stabilised with PE is higher than that of soils stabilised with PP. AlAfandi (2015) used polyethylene waste material (water bottles) in the form of fibres with cement to enhance the compressive and tensile strength of clayey soils. The fibre contents consisted of $0.4 \%, 0.8 \%$, and $1.2 \%$ of the soil dry weight, and the fibre lengths were $1.0 \mathrm{~cm}, 2.0 \mathrm{~cm}$, and $3.0 \mathrm{~cm}$. He found that soil stabilised with fibre was more efficient in the unconfined compressive strength (UCS) than in the tensile strength. The optimum fibre content and fibre length were $1.2 \%$ and $2.0 \mathrm{~cm}$, respectively.

It can be seen from Table 4 that the increase in fibre content increases the UCS up to specific fibre content and then decreases. According to Naeini and Sadjadi (2008), the increase in fibre content above a specific percentage leads to slippage of fibre panels over each other and causes soil particles to separate, thus, it decreases the strength of the soil. The UCS results clearly showed that longer fibre lengths $(2.0 \mathrm{~cm})$ have higher increase in strength than shorter fibre lengths $(1.0 \mathrm{~cm})$. Many researchers have studied the effect of PE on UCS of soils with similar results (Puppala and Musenda 2007; Naeini and Sadjadi 2008; Ghorbani et al. 2018; Oliveira et al. 2018; Zukri et al. 2017; 
Table 4 CBR test results for PE fibres of $1 \mathrm{~cm}$ and $2 \mathrm{~cm}$ in length

\begin{tabular}{llll}
\hline Fibre content $(\%)$ & Fibre length $(\mathrm{cm})$ & CBR $(\%)$ PE & CBR (\%) PP \\
\hline 0 & - & 4.0 & 4.0 \\
1 & 1 & 4.9 & 4.2 \\
& 2 & 5.4 & 4.8 \\
2 & 1 & 5.1 & 4.9 \\
& 2 & 6.0 & 5.1 \\
3 & 1 & 5.9 & 5.3 \\
& 2 & 6.7 & 5.6 \\
4 & 1 & 6.2 & 5.7 \\
& 2 & 7.2 & 6.0 \\
\hline
\end{tabular}

Pal et al. 2015; Sharma 2017; Franco et al. 2014; Louzada et al. 2019; Sai and Srinivas 2019). Their results revealed that the addition of PE and PP significantly increases the UCS of soil. However, the study shall optimise the percentage of fibre content; in this study for example, the strength decreases as the fibre content increases from $1 \%$ to $2 \%$ fibre content; therefore, a smaller percentage fraction can be tried such as $0.5 \%$ increment to find the optimum fibre content, which gives the highest UCS values (Fig. 12).

\subsection{California Bearing Ratio (CBR) Test}

Table 4 shows the results of the CBR test. The CBR value for the native soil was $4 \%$. As it can be seen, the addition of PE and PP fibre to the clayey soil increased the strength considerably compared to the native soil strength. In addition, this increase in

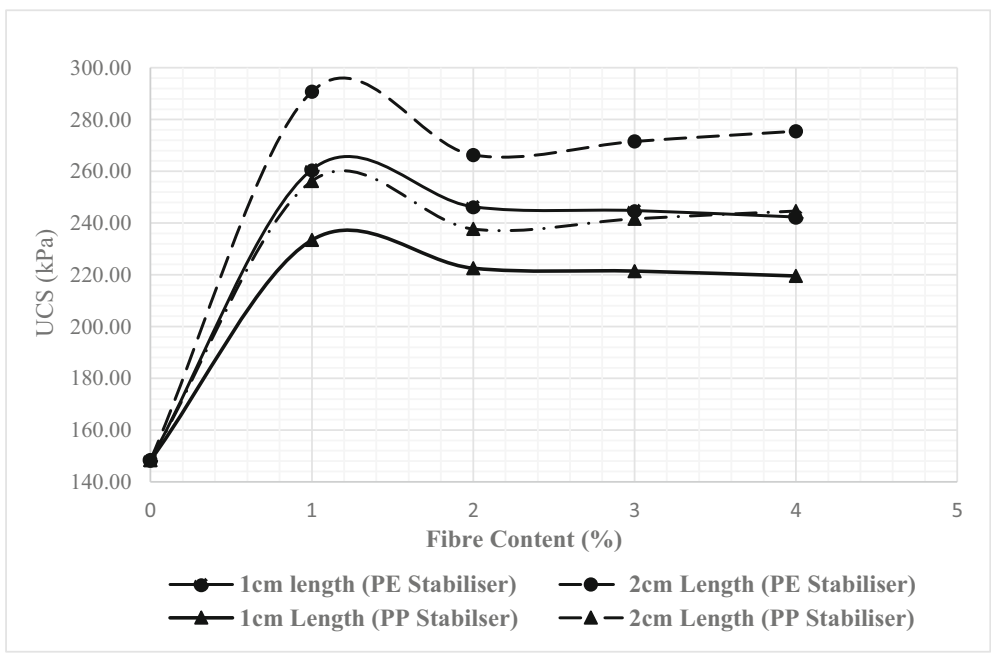

Fig. 12 UCS test results for PE and PP with 1-cm and 2-cm lengths at different fibre contents 


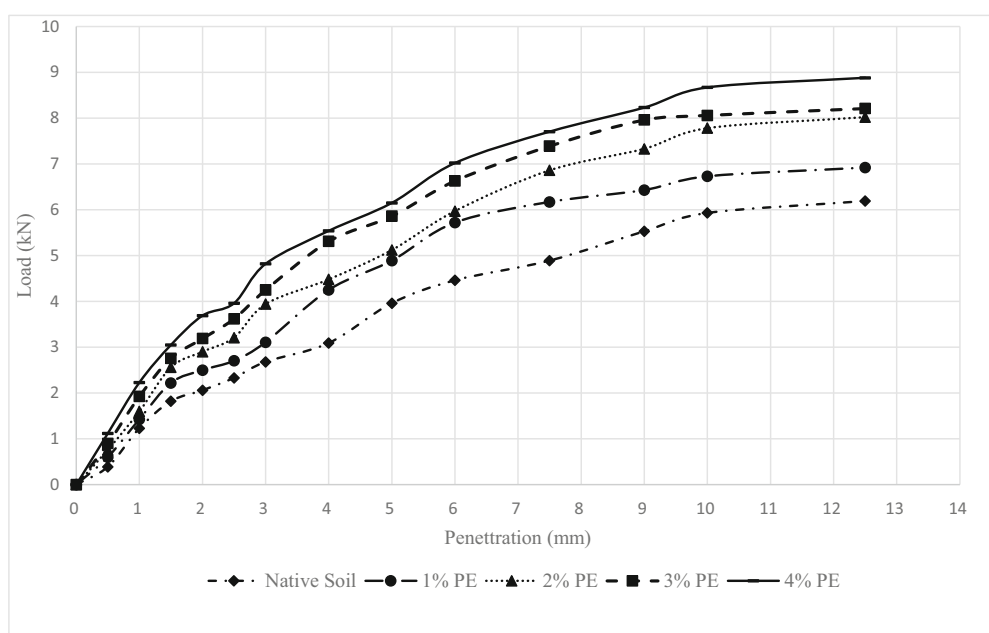

Fig. 13 CBR test profile for 1-cm length of PE

CBR can be noticed with an increase in the fibre content ratio for both types of stabilisers and fibre lengths. The comparison between PE and PP shows that the first one has higher CBR values than the second one for $1.0-\mathrm{cm}$ and $2.0-\mathrm{cm}$ lengths of the fibre. Figures 13, 14, 15, and 16 show the profile of penetration versus the load in the CBR test increasing CBR by $55 \%$ (from 4.0 to 6.2 ) and $80 \%$ (from 4.0 to 7.2 ), respectively.

For the soil stabilised with PE, the addition of $1.0-\mathrm{cm}$ and $2.0-\mathrm{cm}$ lengths of PE fibre increased the CBR values by $55 \%$ (from 4.0 to 6.2 ) and $80 \%$ (from 4.0 to 7.2 ), respectively. And for the soil stabilised with PP, the addition of $1.0-\mathrm{cm}$ and $2.0-\mathrm{cm}$ lengths of PP fibre increased CBR by $42.5 \%$ (from 4.0 to 5.7 ) and $50 \%$ (from 4.0 to 6.0 ), respectively. These results clearly revealed that the fibre content and fibre length

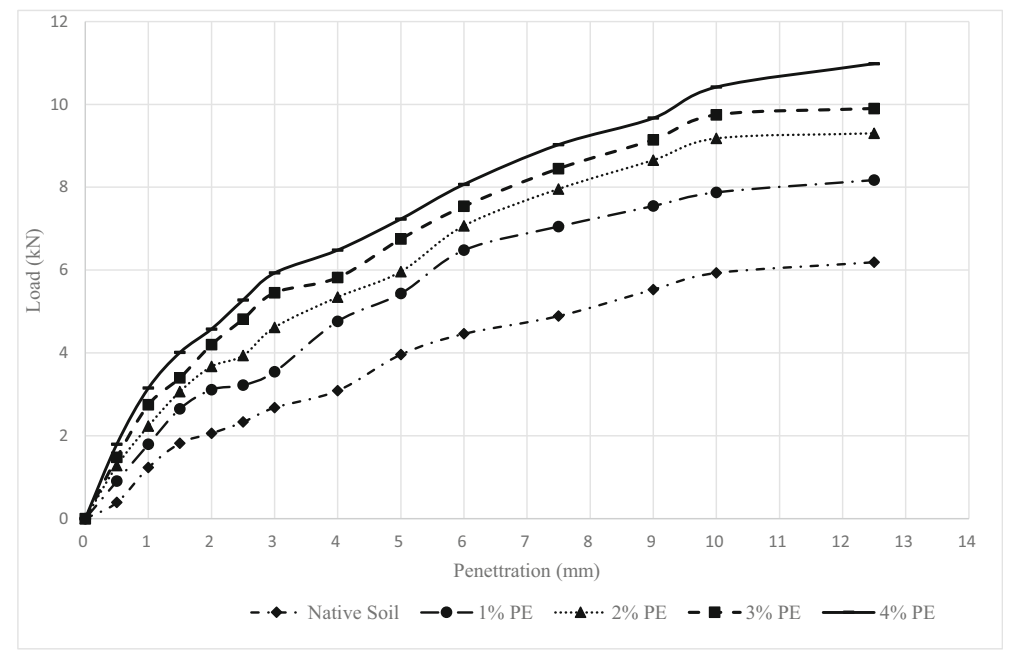

Fig. 14 Test profile for 2-cm length of PE 


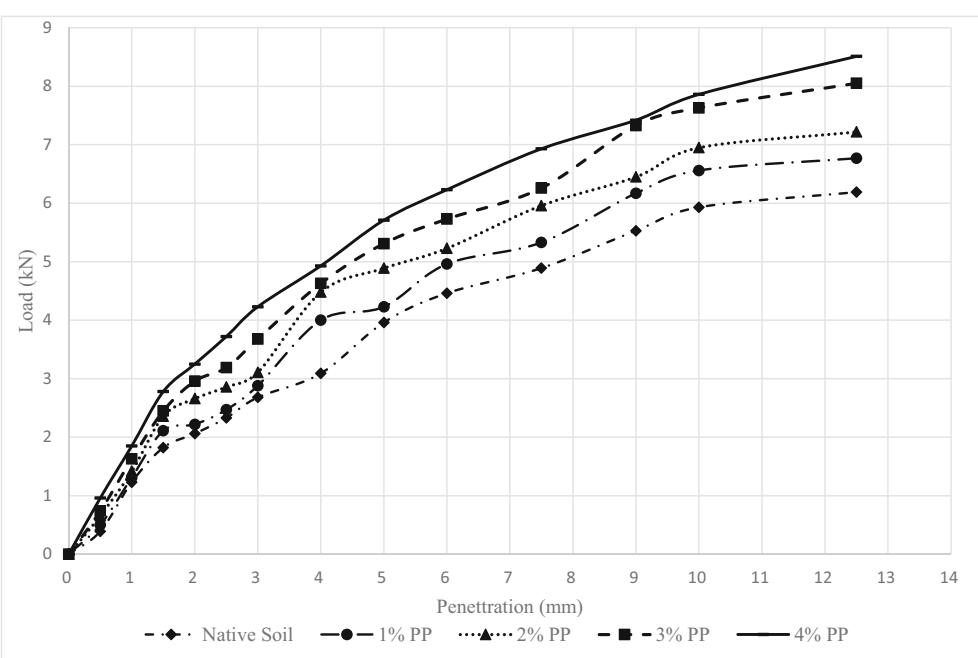

Fig. 15 CBR test profile for 1-cm length of PP

have significant effects on CBR values, and this was also confirmed by Ashraf (2011). The increase in the CBR value with the inclusion of plastic fibre is generally due to the soil and fibre interactions as it provides resistance to the penetration plunger; and consequently, increases in the CBR value (Neopaney et al. 2012; Yetimoglu and Salbas 2003) are also confirmed through this behaviour. Choudhary et al. (2010) found that the stabilisation of soils with polyethylene fibres improved CBR values three times than the non-stabilised soils. Fletcher and Humphries (1991) stabilised soil samples with polypropylene fibres and found that $\mathrm{CBR}$ of the stabilised soil was highly improved especially at longer fibres. Also, Madavi and Patel (2017) concluded that $4 \%$ is the optimum content of plastics for obtaining the highest CBR value. Kumar et al. (2018)

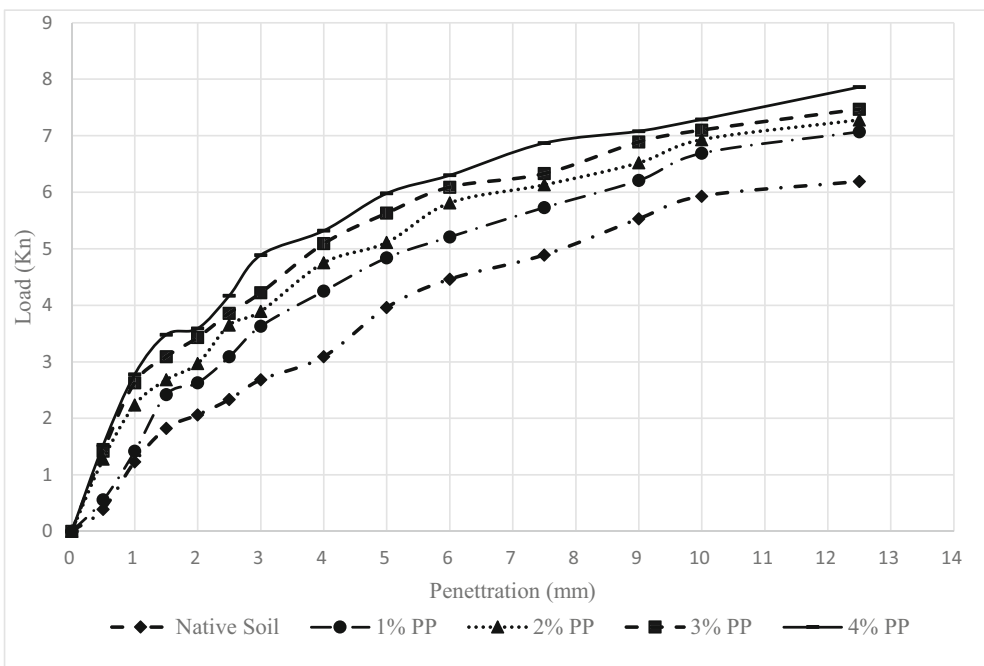

Fig. 16 CBR test profile for 2-cm length of PP 
investigated that $2.0-\mathrm{cm}$ fibre length is the optimum fibre plastic length to obtain the maximum CBR value. This increase in CBR values of subgrade soils can have significant impact on required foundation thicknesses, especially for those pavement design methods such as Design Manual for Roads and Bridges (DMRB) of Highway England, in which the thickness of the pavement foundation is depending on the CBR and modulus of elasticity of subgrades. The increase in subgrade CBR and modulus of elasticity reduces the required sub-base thickness considerably and results in the reduction in road pavement construction costs.

\subsection{Resilient Modulus (Mr) Test}

Tables 5, 6, 7, and 8 show the resilient modulus test results for the native soil and stabilised soils with two different types of fibres at four ratios of fibre content. In general, the increase in deviatoric stress for coarse-grained soils results in the increase in resilient modulus, while fine-grained soils behave the opposite (Huang 1993). As can be seen from the results, the increase in deviatoric stress in most cases is followed by a decrease in resilient modulus, and a decrease in confining stress results in a decrease in resilient modulus. In all cases, the increase in fibre content resulted in the increase in resilient modulus, this shows the improvement in the behaviour of the stabilised soils, and this can also be explained in a way that the increase in fibre content increases the interconnection between soil particles and subsequent decrease in strains to the applied stresses (Yaghoubi et al. 2016). Figures 17, 18, 19, and 20 show clearly how the change

Table 5 Resilient modulus values of PE at different ratios for 1-cm length

\begin{tabular}{|c|c|c|c|c|c|c|}
\hline \multirow[t]{2}{*}{ Confining pressure $(\mathrm{kPa})$} & \multirow[t]{2}{*}{ Cyclic stress $(\mathrm{kPa})$} & \multicolumn{5}{|c|}{ Fibre content $(\%)$} \\
\hline & & 0 & 1 & 2 & 3 & 4 \\
\hline 41.37 & 24.82 & 140 & 145.2 & 147.9 & 148 & 171 \\
\hline 41.37 & 12.41 & 142 & 144.6 & 155.0 & 168 & 188 \\
\hline 41.37 & 24.82 & 141 & 147 & 153 & 150.4 & 169 \\
\hline 41.37 & 37.23 & 136 & 138.4 & 143.8 & 144 & 158 \\
\hline 41.37 & 49.64 & 134 & 136.6 & 141.8 & 141 & 150 \\
\hline 41.37 & 62.05 & 134.8 & 137.0 & 137.7 & 140.3 & 147 \\
\hline 27.58 & 12.41 & 133.77 & 136.0 & 136.7 & 159 & 172 \\
\hline 27.58 & 24.82 & 133.1 & 135.3 & 141.8 & 151 & 162 \\
\hline 27.58 & 37.23 & 133.4 & 136.1 & 137.7 & 146 & 157 \\
\hline 27.58 & 49.64 & 132.7 & 136.6 & 138.7 & 141 & 147 \\
\hline 27.58 & 62.05 & 133.6 & 137 & 137.7 & 136 & 143 \\
\hline 13.79 & 12.41 & 130 & 137.2 & 138.7 & 148 & 167 \\
\hline 13.79 & 24.82 & 132 & 136.1 & 135.7 & 145 & 149 \\
\hline 13.79 & 37.23 & 132.1 & 135.6 & 136.7 & 144 & 147 \\
\hline 13.79 & 49.64 & 132.3 & 134.3 & 136.5 & 140 & 146.3 \\
\hline 13.79 & 62.05 & 132.5 & 134.2 & 135.7 & 139 & 144 \\
\hline
\end{tabular}


Table 6 Resilient modulus values of PE at different ratios for 2-cm length

\begin{tabular}{|c|c|c|c|c|c|c|}
\hline \multirow[t]{2}{*}{ Confining pressure $(\mathrm{kPa})$} & \multirow[t]{2}{*}{ Cyclic stress $(\mathrm{kPa})$} & \multicolumn{5}{|c|}{ Fibre content $(\%)$} \\
\hline & & 0 & 1 & 2 & 3 & 4 \\
\hline 41.37 & 24.82 & 140 & 144 & 147.9 & 152 & 158 \\
\hline 41.37 & 12.41 & 142 & 158 & 162 & 168 & 170 \\
\hline 41.37 & 24.82 & 141 & 151.3 & 153 & 166 & 163 \\
\hline 41.37 & 37.23 & 136 & 143.2 & 145 & 148 & 154 \\
\hline 41.37 & 49.64 & 134 & 146.9 & 151.2 & 149 & 159 \\
\hline 41.37 & 62.05 & 134.8 & 143.9 & 142 & 146 & 148 \\
\hline 27.58 & 12.41 & 133.77 & 153.7 & 159 & 163.3 & 167 \\
\hline 27.58 & 24.82 & 133.1 & 154.3 & 153 & 154.9 & 163 \\
\hline 27.58 & 37.23 & 133.4 & 140.9 & 142 & 149.9 & 155 \\
\hline 27.58 & 49.64 & 132.7 & 136.6 & 144 & 141 & 143 \\
\hline 27.58 & 62.05 & 133.6 & 140 & 138.2 & 140 & 141 \\
\hline 13.79 & 12.41 & 128 & 145.3 & 148.3 & 153 & 158 \\
\hline 13.79 & 24.82 & 130 & 138.2 & 148 & 147 & 152 \\
\hline 13.79 & 37.23 & 132.1 & 138.7 & 142.11 & 149 & 152 \\
\hline 13.79 & 49.64 & 132.3 & 140 & 137.7 & 142 & 149 \\
\hline 13.79 & 62.05 & 132.5 & 137 & 139 & 143 & 142 \\
\hline
\end{tabular}

Table 7 Resilient modulus values of PP at different ratios for 1-cm length

\begin{tabular}{|c|c|c|c|c|c|c|}
\hline \multirow[t]{2}{*}{ Confining pressure $(\mathrm{kPa})$} & \multirow[t]{2}{*}{ Cyclic stress $(\mathrm{kPa})$} & \multicolumn{5}{|c|}{ Fibre content $(\%)$} \\
\hline & & 0 & 1 & 2 & 3 & 4 \\
\hline 41.37 & 24.82 & 140 & 142.1 & 144.2 & 143.2 & 142.8 \\
\hline 41.37 & 12.41 & 142 & 144.3 & 146.6 & 145.3 & 144.6 \\
\hline 41.37 & 24.82 & 141 & 143.56 & 145.2 & 145.1 & 144.8 \\
\hline 41.37 & 37.23 & 136 & 138.97 & 139.7 & 139.1 & 139.1 \\
\hline 41.37 & 49.64 & 134 & 136.6 & 140 & 138.8 & 138.7 \\
\hline 41.37 & 62.05 & 134.8 & 135.8 & 138 & 137.3 & 136.7 \\
\hline 27.58 & 12.41 & 133.77 & 135.7 & 137.5 & 137.1 & 136.9 \\
\hline 27.58 & 24.82 & 133.1 & 135.32 & 138.2 & 137.5 & 136.4 \\
\hline 27.58 & 37.23 & 133.4 & 134.88 & 136.7 & 135.6 & 135 \\
\hline 27.58 & 49.64 & 132.7 & 134.55 & 135.4 & 134.8 & 134.2 \\
\hline 27.58 & 62.05 & 133.6 & 135.2 & 137.4 & 136.9 & 135.5 \\
\hline 13.79 & 12.41 & 130 & 134.22 & 137.9 & 136.8 & 135.9 \\
\hline 13.79 & 24.82 & 132 & 133.8 & 134.8 & 134.3 & 134 \\
\hline 13.79 & 37.23 & 132.1 & 134.1 & 136.8 & 134.9 & 134.3 \\
\hline 13.79 & 49.64 & 132.3 & 133.3 & 134.5 & 134.1 & 133.9 \\
\hline 13.79 & 62.05 & 132.5 & 133.9 & 134.2 & 134.1 & 134 \\
\hline
\end{tabular}


Table 8 Resilient modulus values of PP at different ratios for 2-cm length

\begin{tabular}{|c|c|c|c|c|c|c|}
\hline \multirow[t]{2}{*}{ Confining pressure $(\mathrm{kPa})$} & \multirow[t]{2}{*}{ Cyclic stress $(\mathrm{kPa})$} & \multicolumn{5}{|c|}{ Fibre content $(\%)$} \\
\hline & & 0 & 1 & 2 & 3 & 4 \\
\hline 41.37 & 24.82 & 140 & 147.2 & 145.3 & 143 & 140 \\
\hline 41.37 & 12.41 & 142 & 150.1 & 146.8 & 144.9 & 142 \\
\hline 41.37 & 24.82 & 141 & 148.6 & 145.2 & 145 & 141 \\
\hline 41.37 & 37.23 & 136 & 142 & 139.7 & 139.4 & 136 \\
\hline 41.37 & 49.64 & 134 & 141.9 & 139.1 & 139 & 134 \\
\hline 41.37 & 62.05 & 134.8 & 140.9 & 137.8 & 137.2 & 134.8 \\
\hline 27.58 & 12.41 & 133.8 & 138.2 & 137.6 & 137 & 133.77 \\
\hline 27.58 & 24.82 & 133.1 & 139.9 & 138.2 & 137.4 & 133.1 \\
\hline 27.58 & 37.23 & 133.4 & 138.2 & 136.4 & 135.8 & 133.4 \\
\hline 27.58 & 49.64 & 132.7 & 138.7 & 135.8 & 135.1 & 132.7 \\
\hline 27.58 & 62.05 & 133.6 & 137.6 & 138.2 & 136.2 & 133.6 \\
\hline 13.79 & 12.41 & 130 & 138.3 & 136.8 & 136.3 & 130 \\
\hline 13.79 & 24.82 & 132 & 135 & 134.8 & 134.2 & 132 \\
\hline 13.79 & 37.23 & 132.1 & 137.2 & 135.6 & 135 & 132.1 \\
\hline 13.79 & 49.64 & 132.3 & 135.3 & 135.3 & 134.9 & 132.3 \\
\hline 13.79 & 62.05 & 132.5 & 134.9 & 135.1 & 134.7 & 132.5 \\
\hline
\end{tabular}

in confining and deviatoric stress affects the change in resilient modulus; this is shown for different stress conditions. Other researches such as Perera et al. (2019), Arulrajah et al. (2017), and Yaghoubi et al. (2016) achieved similar trends. Hafez et al. (2018) investigated the effect of polyethylene terephthalate (PET) on the Mr of clayey soil. The percentages of PET were $0 \%, 0.2 \%, 0.6 \%$, and $1.0 \%$. The test results revealed that

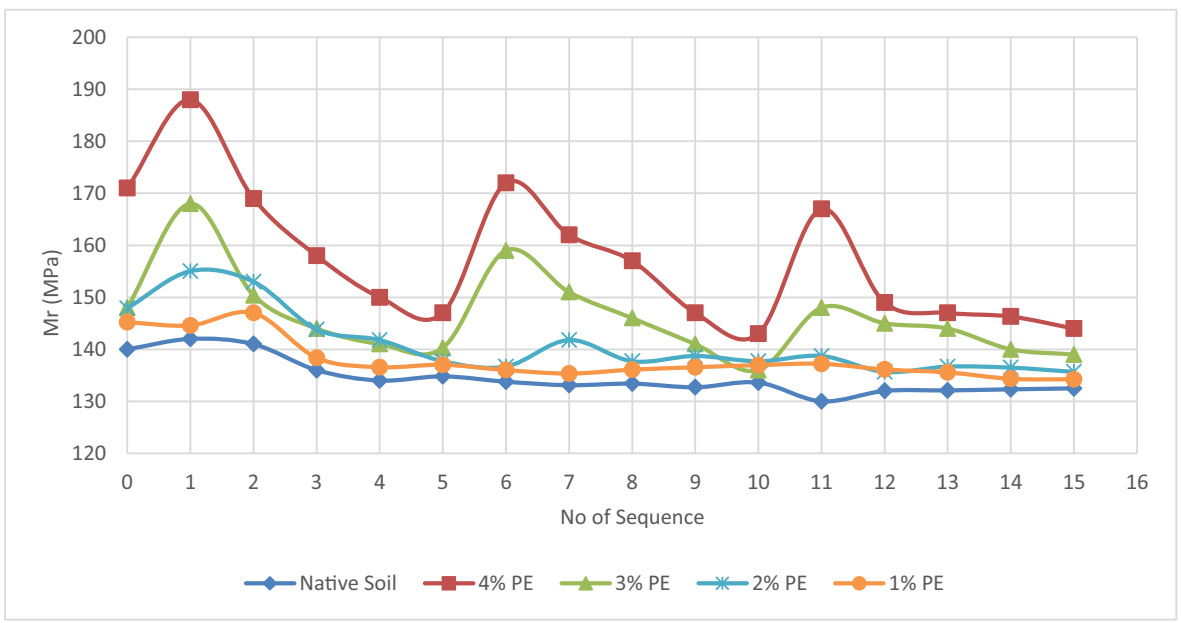

Fig. 17 Resilient modulus of PE at different ratios for 1-cm length 


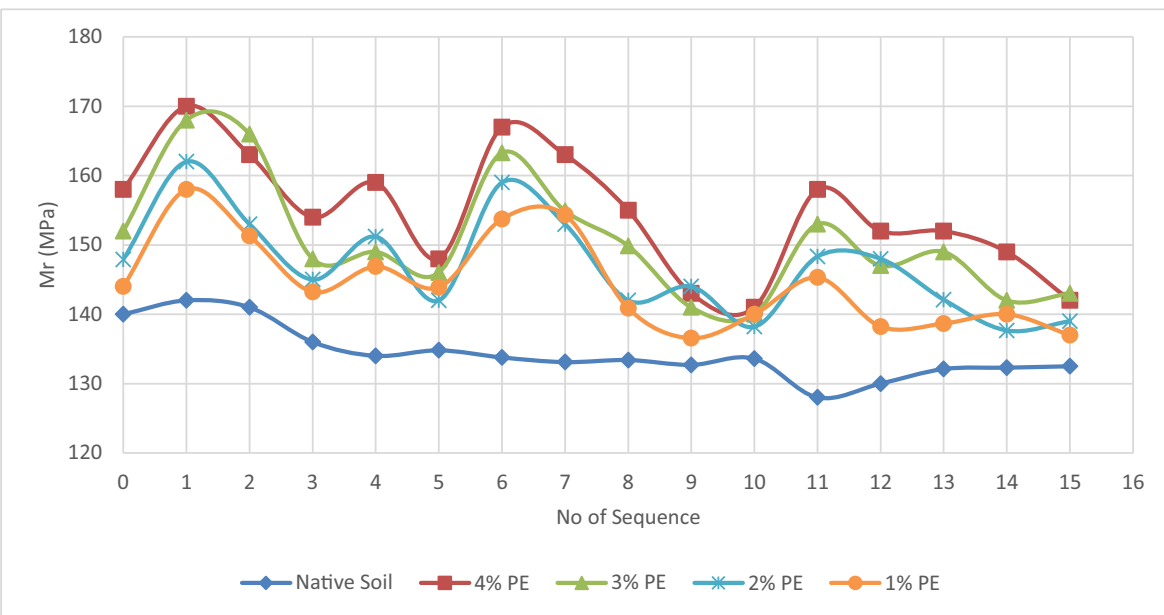

Fig. 18 Resilient modulus of PE at different ratios for 2-cm length

the $\mathrm{Mr}$ of $0.6 \%$ PET-reinforced specimens increases by $58 \%$ compared to the $\mathrm{Mr}$ of the control specimen (0\% PET). Kaushik and Sharma (2019) studied the influence of waste polypropylene fibres on the $\mathrm{Mr}$ of clay soil. The polypropylene fibres were added in various contents of $0.3 \%, 0.4 \%, 0.5 \%$, and $0.6 \%$ by the soil weight. Their studies showed that $0.4 \%$ fibre content was considered the optimum fibre content to obtain the maximum $\mathrm{Mr}$ value.

Generally, the results showed that the soils stabilised with PE obtained higher Mr values than the soils stabilised with PP. In addition, for both PE fibre lengths by increasing the fibre content, $\mathrm{Mr}$ values increased. The results revealed that $2.0-\mathrm{cm} \mathrm{PE}$ fibre length has higher Mr than 1.0-cm PE fibre length. For the stabilisation of soils with $\mathrm{PP}, \mathrm{Mr}$ values increased to some extent; then, these values were decreased. The optimum fibre content was $2 \%$ for both PP fibre lengths. Studies by Ahmadinia et al.

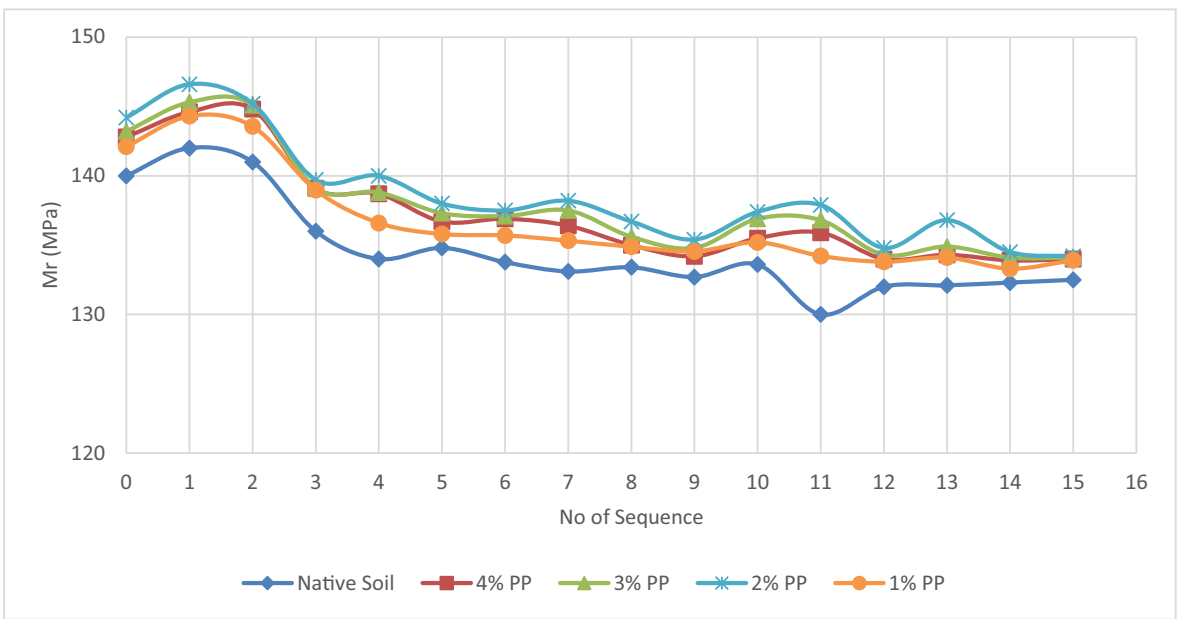

Fig. 19 Resilient modulus of PP at different ratios for 1-cm length 


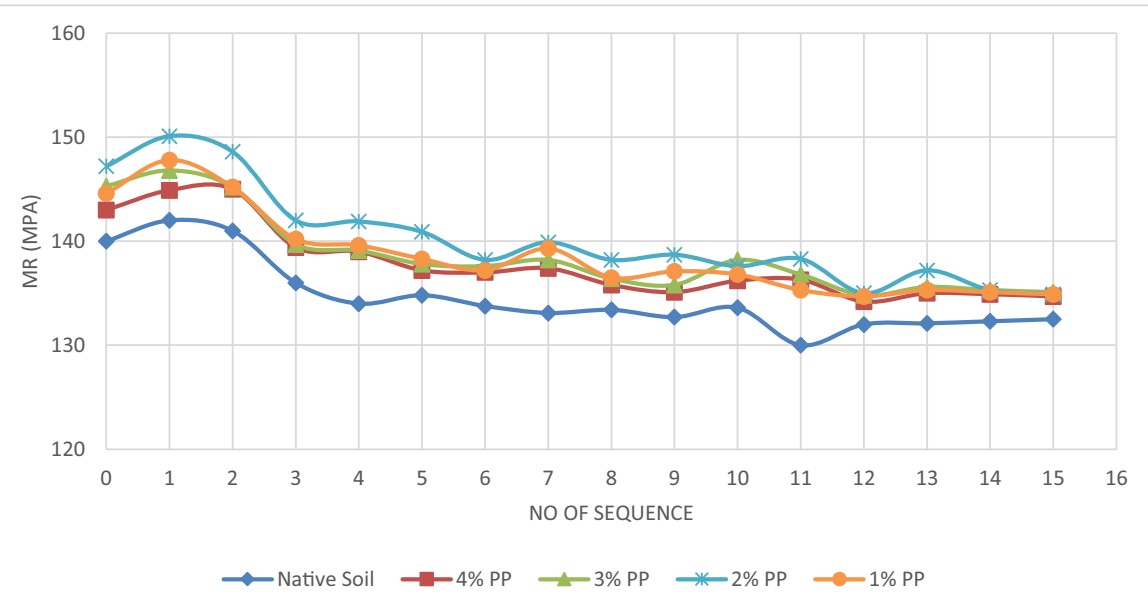

Fig. 20 Resilient modulus of PP at different ratios for 2-cm length

(2012) and Perera et al. (2019) revealed that by adding PE materials, Mr values increased. Perera et al. (2019) found that the addition of PE and the increasing deviatoric stress at the same confining pressure result in higher Mr values. Research by Phillip and Cameron (1995), Onyelowe et al. (2019), Hafez et al. (2018), and Ramesh et al. (2019) found that the Mr value improved with the addition of fibre plastics.

To calculate the improvement in the mechanical behaviour of the soils stabilised with fibres, a pavement section was analysed using the KENLAYER programme; for simplicity, the linear elastic method was followed. The load of the tyre was simulated to have a circular shape with a diameter of $152 \mathrm{~mm}$ and a pressure of $860 \mathrm{kPa}$. The proposed pavement section has dimensions and properties as presented in Table 9. In Table 9, the values of the modulus of elasticity of the asphalt and granular layers were $4000 \mathrm{MPa}$ and $200 \mathrm{MPa}$, respectively, and the stabilised subgrade layer's modulus was taken to be variable according to the different scenarios of the soil stabilisation.

The results from the analyses are presented in Table 10. As can be seen, the compressive strain at the top of the subgrade soil is improved with the increase in fibre content from 0 to $4 \%$ and with the increase in fibre length from 1.0 to $2.0 \mathrm{~cm}$. The same trend can be noticed for the surface deflection, although it is not a road pavement design criterion. Since the asphalt concrete layer was taken to be constant for all scenarios, the tensile strain at the bottom of the layer is not changed. Research by Rasul et al. (2016) and Rasul et al. (2018) showed that the stabilisation with cement and lime and combinations of both resulted in a significant increase in UCS and Mr values with the increase in the stabiliser content. While in this research, the stabilisation with fibre showed an

Table 9 Pavement section dimensions

\begin{tabular}{llll}
\hline Layer & Thickness $(\mathrm{m})$ & Resilient modulus (MPa) & Poisson's ratio \\
\hline Asphalt concrete & 0.10 & 4000 & 0.4 \\
Unbound granular & 0.20 & 200 & 0.3 \\
Subgrade & - & Variable & 0.45 \\
\hline
\end{tabular}


Table 10 Results of the analyses of the pavement section

\begin{tabular}{|c|c|c|c|c|c|c|}
\hline Fibre type & Fibre length (mm) & $\begin{array}{l}\text { Fibre content } \\
(\%)\end{array}$ & $\begin{array}{l}\text { Vertical } \\
\text { coordinate } \\
\text { (z) }(\mathrm{mm})\end{array}$ & $\begin{array}{l}\text { Deflection } \\
(\mathrm{mm})\end{array}$ & $\begin{array}{l}\text { Vertical strain } \\
\text { ( } \mu \text { strain) }\end{array}$ & $\begin{array}{l}\text { Radial strain } \\
\text { ( } \mu \text { strain) }\end{array}$ \\
\hline \multirow[t]{30}{*}{$\mathrm{PE}$} & \multirow[t]{15}{*}{10} & \multirow[t]{3}{*}{0} & 0.000 & 0.678 & -387 & 366 \\
\hline & & & 10.000 & 0.678 & 570 & -401 \\
\hline & & & 30.001 & 0.472 & 811 & -350 \\
\hline & & \multirow[t]{3}{*}{1} & 0.000 & 0.674 & -386 & 365 \\
\hline & & & 10.000 & 0.674 & 569 & -400 \\
\hline & & & 30.001 & 0.468 & 804 & -347 \\
\hline & & \multirow[t]{3}{*}{2} & 0.000 & 0.670 & -385 & 364 \\
\hline & & & 10.000 & 0.670 & 569 & -400 \\
\hline & & & 30.001 & 0.464 & 798 & -344 \\
\hline & & \multirow[t]{3}{*}{3} & 0.000 & 0.661 & -383 & 363 \\
\hline & & & 10.000 & 0.661 & 567 & -399 \\
\hline & & & 30.001 & 0.455 & 785 & -339 \\
\hline & & \multirow[t]{3}{*}{4} & 0.000 & 0.650 & -380 & 361 \\
\hline & & & 10.000 & 0.650 & 566 & -397 \\
\hline & & & 30.001 & 0.443 & 766 & -330 \\
\hline & \multirow[t]{15}{*}{20} & \multirow[t]{3}{*}{0} & 0.000 & 0.678 & -387 & 366 \\
\hline & & & 10.000 & 0.678 & 570 & -401 \\
\hline & & & 30.001 & 0.472 & 811 & -350 \\
\hline & & \multirow[t]{3}{*}{1} & 0.000 & 0.666 & -385 & 364 \\
\hline & & & 10.000 & 0.666 & 568 & -399 \\
\hline & & & 30.001 & 0.460 & 793 & -342 \\
\hline & & \multirow[t]{3}{*}{2} & 0.000 & 0.661 & -383 & 363 \\
\hline & & & 10.000 & 0.661 & 567 & -399 \\
\hline & & & 30.001 & 0.455 & 785 & -339 \\
\hline & & \multirow[t]{3}{*}{3} & 0.000 & 0.652 & -381 & 361 \\
\hline & & & 10.000 & 0.652 & 566 & -397 \\
\hline & & & 30.001 & 0.445 & 770 & -332 \\
\hline & & \multirow[t]{3}{*}{4} & 0.000 & 0.654 & -381 & 361 \\
\hline & & & 10.000 & 0.654 & 566 & -398 \\
\hline & & & 30.001 & 0.447 & 773 & -333 \\
\hline
\end{tabular}

Bold entries indicates the results where deflection, stress and strain within the pavemnet layers are important and used for comparison and design

increase in UCS to a specified ratio of fibre content beyond which the UCS decreases, but there is an increase in Mr values. This can be a major difference between using chemical agents and fibres for stabilisation, in which it can be decided to choose the most suitable stabiliser for the corresponding required properties. For example, for subgrade soils in which the resilient modulus is an essential property to improve, fibre can be used, and for other purposes in which UCS is an important property, a chemical agent would be more favourable. 


\section{Concluding Discussion}

Stabilisation considerably improves the engineering properties of soils, and this includes physical, strength, and mechanical properties. This paper has investigated these properties through an experimental laboratory test programme on two different waste materials that can be found in disposal bins, namely, polyethylene and polypropylene. The main conclusions from the study carried out herein are summarised as follows:

(1) Soil stabilisation with fibre has different trends for UCS and Mr, as the increase in fibre content is not resulting in the increase in UCS ascendingly, while for Mr, the increase in fibre content resulted in the increase in Mr values. Therefore, optimum fibre content shall be sought for stabilisation with fibres for the highest values of UCS and Mr.

(2) PE and PP can efficiently be used to improve the physical and strength properties of soil materials as a foundation for engineering projects.

(3) The length of the fibre showed to have an effect on the strength properties of the stabilised soil, as the increase in length resulted in higher strength properties. This may require more research to find the optimum fibre length that gives the highest strength properties.

(4) For those road pavement design codes of practice that use the CBR and $\mathrm{Mr}$ as design parameters, the fibre stabilisation is cost-effective and it can be used successfully for a sustainable road construction if compared with chemically stabilised soils. The stabilisation with chemical agents is accompanied by carbon dioxide emission, while fibre stabilisation is not; this is one of the advantages of fibre stabilisation over chemical stabilisation.

(5) While for CBR and $\mathrm{Mr}$, the increase in fibre content resulted in the increase in value, for UCS, the optimum fibre content could be found between $1 \%$ and $2 \%$ fibre content for both PE and PP.

Acknowledgements The authors would like to express their gratitude to the Department of Civil Engineering at the University of Duhok for the provision of laboratory facilities to enable the research.

Author Contributions All authors contributed to the study conception and design. Hussein Jalal prepared data collection, and the analysis was performed by Hussein Jalal, Jabar Rasul, and Maleaha Samin. Hussein Jalal wrote the first draft of the manuscript, and all authors commented on the previous versions of the manuscript. All authors read and approved the final manuscript.

Funding This research has been funded by the Department of Civil Engineering at the University of Duhok.

\section{Compliance with Ethical Standards}

Conflict of Interest The authors declare that they have no conflict of interest.

Open Access This article is licensed under a Creative Commons Attribution 4.0 International License, which permits use, sharing, adaptation, distribution and reproduction in any medium or format, as long as you give appropriate credit to the original author(s) and the source, provide a link to the Creative Commons licence, and indicate if changes were made. The images or other third party material in this article are included in the article's Creative Commons licence, unless indicated otherwise in a credit line to the material. If material is not 
included in the article's Creative Commons licence and your intended use is not permitted by statutory regulation or exceeds the permitted use, you will need to obtain permission directly from the copyright holder. To view a copy of this licence, visit http://creativecommons.org/licenses/by/4.0/.

\section{References}

Ahmadinia, E., Zargar, M., Karim, M., Abdelaziz, M., Ahmadinia, E.: Performance evaluation of utilization of waste polyethylene terephthalate (PET) in stone mastic asphalt. Constr. Build. Mater. 36(2012), 984-989 (2012)

AlAfandi, Z.M.S.: Effect of polyethylene waste fibres on strength of cement stabilized clayey soil. J. Univ. Duhok. 18(1) Pure and Eng. Sciences, 1-12 (2015)

Arulrajah, A., Yaghoubi, E., Arulrajah, A., Wong, Y.C., Horpibulsuk, S.: Recycled plastic granules and demolition wastes as construction materials: resilient moduli and strength characteristics. Constr. Build. Mater. 147(2017), 639-647 (2017)

Ashraf, A., Sunil, A., Dhanya, D., Joseph, M., Joseph, M., Veena, M, (2011) Soil stabilisation using raw plastic bottles. Proceedings of Indian Geotechnical Conference December 15-17, 2011, Kochi (Paper No. H-304).

Awuchi, C.G.: Impacts of plastic pollution on the sustainability of seafood value chain and human health. Int. J. Adv. Acad. Res. 5(11), 46-138 (2019)

Babu, S.G.L., Chouksey, S.K.: Stress-strain response of plastic waste mixed soil. Waste Manag. J. 31, 481488 (2011)

Bala, R.-p.: A study on CBR behaviour of waste plastic (PET) on stabilised red mud and fly ash. Int. J. Struct. Civil Engg. Res. 2013 (2013)

Bell, F.: Lime stabilisation of clay minerals and soils. Eng. Geol. 42, 223-237 (1996)

Changizi, F., Haddad, A.: Strength properties of soft clay treated with mixture of nano-SiO2 and recycled polyester fiber. Journal of Rock Mechanics and Geotechnical Engineering 7(4), 367-378 (2015)

Chauhan, R., Kumar, A., Kumar, A.: A review of utilization of cut waste plastic and crushed waste glass in soil stabilisation. Discovery. 41(186), 15-19 (2015)

Choudhary, A.K., Jha, J.N., Gill, K.S.: A study on CBR behaviour of waste plastic strip reinforced soil. Emirates J. Eng. Res. 15(1), 51-57 (2010)

Dhatrak, A., Konmare, S.D.: Performance of randomly oriented plastic waste In Flexible Pavement. International JPRET, 2015. 3(9), 193-202 (2015a)

Dhatrak A and Konmare SD(2015b) Performance of randomly oriented plastic waste In Di Emidio, G., Meeusen, J., Snoeck, D., and Flores, R. (2018) Enhanced Sustainable Soils: A Review. The International Congress on Environmental Geotechnics (ICEG 2018): Proceedings of the 8th International Congress on Environmental Geotechnics Volume 3 pp. 515-522.

Fauzi, A., Djauhari, Z., Fauzi, U.J.: Soil engineering properties improvement by utilisation of cut waste plastic and crushed waste glass as additive. Int. J. Eng. Technol. (1), 8 (2015) Jan 2015

Fletcher, C., Humphries, W.: California Bearing Ratio improvement of remoulded soils by the addition of polypropylene fibre reinforcement. Transp. Res. Rec. 1295, 80-86 (1991)

Franco, A., Malhotra, N., Simonovits, G.: Publication bias in the social sciences: Unlocking the file drawer. Science 345(6203), 1502-1505 (2014)

Gardete, D.; Luzia, R.; Sousa, M.; Carronda, S.; Simão, A. : Soil stabilisation with waste plastic and waste tyre fibres. Proceedings of the XVII European Conference on Soil Mechanics and Geotechnical Engineering (ECSMGE). ISBN 978-9935-9436-1-3. (2019) https://doi.org/10.32075/17ECSMGE-2019-0894.

Ghorbani, A., Salimzadehshooiili, M., Medzvieckas, J., Kliukas, R.: Strength characteristics of cement-rice husk ash stabilised sand-clay mixture reinforced with polypropylene fibres. Balt. J. Road Bridge Eng. 13(4), 447-474 (2018)

Hafez, M., Mousa, R., Awed, A., El-Badawy, S.: Soil reinforcement using recycled plastic waste for sustainable pavements. In: ElBadawy, S., Valentin, J. (eds.) Sustainable Solutions for Railways and Transportation Engineering. GeoMEast, vol. 2018, pp. 7-20. Sustainable Civil Infrastructures. Springer, Cham (2018)

Hanna, T., Mosa, I.: Effect of using waste polyethylene production on mechanical properties of concrete. J. Univ. Duhok. 15(1), 37-46 (2012)

Huang, Y.H.: Pavement analysis and design. Englewood Cliffs, N.J., Prentice Hall (1993)

Kaushik, R., Sharma, T.: Influence of waste polypropylene fibres on resilient modulus of clay soil. Int. J. Res. Advent Technol. 7(1), 251-255 (2019) 
Khattab, S.A., Al-Kiki, I.M., Al-Zubaydi, A.H.: Effect of fibres on some engineering properties of cement and lime stabilised soils. Eng. Tech. J. 29(5), 886-905 (2011)

Kumar, T., Panda, S., Hameed, S., Maity, J.: Behaviour of soil by mixing of plastic strips. Int. Res. J. Eng. Technol. 05(05), (2018)

Little, D. N.: Stabilisation of pavement subgrades and base courses with lime. 1995

Louzada, N., Malko, J., Casagrande, M.: Behaviour of clayey soil reinforced with polyethylene terephthalate. J. Mater. Civ. Eng. 31(10), (2019)

Madavi, S., Patel, D.: Soil stabilisation using plastic waste. Int. J. Res. Sci. Eng. 3(2), (2017)

Modarres, A., Hamedi, H.: Effect of waste plastic bottles on the stiffness and fatigue properties of modified asphalt mixes. Mater. Des. 61(2014), 8-15 (2014)

Mondal, P.K.: Behaviour of a clayey soil mixed with plastic waste. Thesis of Civil Engineering Dept. In: Jadavpur University Kolkata (2012)

Muntohar, A.S.: Influence of plastic waste fibers on the strength of lime-rice husk ash stabilized clay soil. Civil Engineering Dimension 11(1), 32-40 (2009)

Muntohar, A.S., Widianti, A., Hartono, E., Diana, W.: Engineering properties of silty soil stabilized with lime and rice husk ash and reinforced with waste plastic fiber. J. Mater. Civ. Eng. 25(9), 1260-1270 (2013)

Naeini, S. and Sadjadi, S.:, Effect of waste polymer materials on shear strength of unsaturated clays, EJGE J., Vol 13, Bund k, (1-12) (2008)

Neopaney, M., Ugyen, K., Tenzin, S.: Stabilisation of soil by using plastic wastes, Int. J. Emerging Trends Eng. Dev. 2(2), (2012)

Nsaif, M.: Behaviour of soils strengthened by plastic waste materials. J. Eng. Sustain. Dev, ISSN: 25200917 Year: 2013. 17(4), 182-194 (2013)

Obo, C. and Ytom, A.: Study on the use of plastic fibre materials as an alternative solution for soil stabilisation). BSc project. The Faculty of Engineering Department University of Southeastern Philippines. Bislig Campus. (2014)

Olgun, M.: Effects of polypropylene fibre inclusion on the strength and volume change characteristics of cement-fly ash stabilised clay soil. Geosynth. Int. 20(4), 263-275 (2013)

Oliveira, P., Correia, A., Cajada, J.: Effect of the type of soil on the cyclic behaviour of chemically stabilised soils unreinforced and reinforced with polypropylene fibres. Soil Dyn. Earthq. Eng. 115, 336-343 (2018)

Onyelowe, K.; Van, D.; Van, M. Ezugwu, C; Amhadi, T.; Sosa, F.; Wu, W.; Duc, T., Orji,F.; Alaneme, G. (2019). Experimental assessment of subgrade stiffness of lateritic soils treated with crushed waste plastics and ceramics for pavement foundation. Int. J. Low Carbon Tech., Volume 14, Issue 2. Pages 187-204.

Pal, S., Sonthwal, V., Rattan, J.: Soil stabilisation using polypropylene as waste fibre material. Int. J. Innov. Res. Sci. Eng. Technol. 4(11), (2015) November 2015

Peddaiah, S., Burman, A., Sreedeep, S.: Experimental study on effect of waste plastic bottle strips in soil improvement. Geotech. Geol. Eng. 36(5), 2907-2920 (2018)

Perera, S., Arulrajah, A., Wong, Y., Horpibulsuk, S., Maghool, F.: Utilizing recycled PET blends with demolition wastes as construction materials. J. Constr. Build. Mater. 221, 200-209 (2019)

Phillip, W., Cameron, A.: The influence of soil suction on the resilient modulus of expansive soil subgrades. Proceedings of the 1st international conference on Unsaturated Soils. Paris. 171-176 (1995)

Puppala, A., Musenda, C.: Effects of fibre reinforcement on strength and volume change in expansive soils. J. Transp. Res. Board. 134-140 (2007)

Ramesh, A., Rao, C., Kumar, M.: Experimental study on geocell and of fibre reinforced soil sub-grade under static and repetitive load. Geotech. Transp. Infrastructure. 139-149 (2019)

Rasul, J., Ghataora, G., Burrow, M.: Permanent deformation of stabilised subgrade soils. In: Bituminous Mixtures and Pavements VI, p. 41 (2015)

Rasul, J.M., Burrow, M.P., Ghataora, G.S.: Consideration of the deterioration of stabilised subgrade soils in analytical road pavement design. Transp. Geotech. 9, 96-109 (2016)

Rasul, J.M., Ghataora, G.S., Burrow, M.P.: The effect of wetting and drying on the performance of stabilised subgrade soils. Transp. Geotech. 14, 1-7 (2018)

Rawat, P. and Kumar, A.: Study of CBR behaviour of soil reinforced with HDPE strips. Indian Geotechnical Conference IGC2016, IIT Madras, Chennai, India. (2016)

Rout, R.K., Ruttanapormakul, P., Valluru, S., Puppala, A.J.: Resilient moduli behaviour of lime-cement treated subgrade soils. Geo Congress, ASCE. 1428-1437 (2012)

Sai, M., Srinivas, V.: Soil stabilisation by using plastic waste granules materials. J. Comput. Eng. (IOSR-JCE). 21(4), 42-51 (2019)

Salimi, K. and Ghzavi, M.: Soil reinforcement and slope stabilisation using recycled waste plastic sheets. (2019) 
Sharma, R.: Laboratory study on stabilisation of clayey soil with cement kiln dust and fibre. J. Geotech. Geoenviron. Eng. 35, 2291-2302 (2017)

Sherwood, P.: Soil stabilization with cement and lime. (1993)

Taha, M.M., Feng, C.P., Ahmed, S.H.: Influence of polypropylene fibre (PF) reinforcement on mechanical properties of clay soil. Adv. Polym. Technol. 2020, (2020)

Tang, C.S., Shi, B., Gao, W., Chen, F., Cai, Y.: Strength and mechanical behaviour of short polypropylene fibre reinforced and cement stabilised clayey soil. Geotext. Geomembr. 25(3), 194-202 (2007a)

Tang, C., Shi, B., Gao, W., Chen, F., Cai, Y.: Strength and mechanical behaviour of short polypropylene fibre reinforced and cement stabilised clayed soil. Geotext. Geomemb. C. 25, 194e202 (2007b)

Tatone, C., Di Emidio, G., Barbonetti, A., Carta, G., Luciano, A.M., Falone, S., Amicarelli, F.: Sirtuins in gamete biology and reproductive physiology: emerging roles and therapeutic potential in female and male infertility. Hum. Reprod. Update 24(3), 267-289 (2018)

Yadav, J.S., Tiwari, S.K.: Behaviour of cement stabilized treated coir fibre-reinforced clay-pond ash mixtures. J. Build. Eng. 8, 131-140 (2016)

Yadav, J.S., Tiwari, S.K.: Effect of waste rubber fibres on the geotechnical properties of clay stabilized with cement. Appl. Clay Sci. 149, 97-110 (2017)

Yadav, J.S., Tiwari, S.K., Shekhwat, P.: Strength behaviour of clayey soil mixed with pond ash, cement and randomly distributed fibres. Trans. Infrastructure Geotechnol. 5(3), 191-209 (2018)

Yaghoubi, E., Arulrajah, A., Wong, Y., Horpibulsuk, S.: Stiffness properties of recycled concrete aggregate with polyethylene plastic granules in unbound pavement applications. Journal of Materials in Civil Engineering. J. Mater. Civ. Eng. 29(4), 4016271 (2016)

Yetimoglu, T., Salbas, O.: A study on shear strength of sands reinforced with randomly distributed discrete fibres. Geotext. Geomembr. 21, 103-110 (2003)

Ziegler, S., Leshchinsky, D., Ling, H.I., Perry, E.B.: Effect of short polymeric fibers on crack development in clays. Soils Found. 38(1), 247-253 (1998)

Zukri, A., Nazir, R., Mender, F.: An experimental study on stabilisation of Pekan clay using polyethylene and polypropylene. AIP Conf. Proc. 1892(1), (2017)

Publisher's Note Springer Nature remains neutral with regard to jurisdictional claims in published maps and institutional affiliations.

\section{Affiliations}

\section{Hussein Jalal Aswad Hassan ${ }^{1} \cdot$ Jabar Rasul $^{2} \cdot$ Maleaha Samin $^{3}$}

Hussein Jalal Aswad Hassan

Hussein.hassan@uod.ac

Maleaha Samin

maleaha.samin@amey.co.uk

1 College of Engineering, University of Duhok, Duhok, Kurdistan Region, Iraq

2 Waterman Aspen, Birmingham, UK

3 Amey, Birmingham, UK 